\title{
MEDICAID'S NURSING HOME COVERAGE AND ASSET TRANSFERS ${ }^{1}$
}

\begin{abstract}
Medicaid covers the costs of a long nursing home stay. This coverage may create an incentive for the elderly to transfer their assets to their children in order to qualify for Medicaid before entering a nursing home. Previous researchers had found little evidence that such behavior was widespread or that asset transfers were large. However, data from AHEAD suggest that the self-assessed probability of entering a nursing home is a significant determinant of the likelihood of making an asset transfer. The budgetary implications of these Medicaid-induced asset transfers are probably fairly small, but not insignificant.
\end{abstract}

\author{
William F. Bassett \\ Board of Governors of the Federal Reserve System \\ 20th and C St. NW \\ Mail Stop 84 \\ Washington, DC 22551 \\ wbassett@frb.gov
}

This Draft: March 26, 2004

\footnotetext{
1 The analysis and conclusions set forth are those of the author and do not indicate concurrence by other members of the research staff or the Board of Governors. I thank Robin Lumsdaine, Moshe Buchinsky, Andrew Foster, Rachel Friedberg, Michael Hurd, Angela Merrill, Vince Mor, and Egon Zakrajšek for helpful comments. In addition, I benefited from discussions with seminar participants at Brown University, the Federal Reserve Board, RAND, and the General Accounting Office. Any errors remain my own.
} 


\section{Introduction}

An April 2002 survey by MetLife found that the average annual cost of care in a skilled nursing facility was in excess of $\$ 60,000$ [MetLife 2002]. Overall, the amount of money spent each year on nursing home care has almost doubled over the past decade, to almost $\$ 100$ billion in 2001 (Table 1). Medicare, the primary health insurance of most Americans over age 65 , only covers short nursing home stays for rehabilitation from acute injury or illness; it does not cover the costs of long-term care. Moreover, private long-term care insurance has yet to become a major payment source. Indeed, the share of nursing home costs covered by private third-party payers has stagnated at just more than 10 percent over the past 5 years. As a result, individuals pay a large portion of these expenses out of their own income and assets. When those assets are exhausted, households turn to Medicaid, which has traditionally picked up the remaining nearly 50 percent of nursing home costs. Because Medicaid is means tested, a significant percentage of the nation's elderly may have an incentive to transfer ownership of their assets to younger relatives in order to make themselves eligible for Medicaid benefits and protect their children's inheritances. ${ }^{1}$ If this estate planning strategy were widespread and effective (and a simple search of the internet produces thousands of elder law websites offering these services), it could inflate the cost to the Medicaid system by billions of dollars.

That households would act based on this incentive is broadly consistent with the common finding that means-tested benefit programs have negative effects on savings and on asset accumulation (Powers [1998]; Gruber and Yelowitz [1999]; Hubbard, Skinner,

\footnotetext{
1 Each parent may transfer up to $\$ 10,000$ to each beneficiary, each calendar year, without incurring federal gift taxes. If larger sums are transferred, the tax liability can be deferred until the parent dies, and it is then cancelled if the value of the remaining estate, plus all gifts over $\$ 10,000$, is less than the estate tax exemption.
} 
and Zeldes [1995]). In a more closely related vein, Feinstein and Ho [2000] show that asset transfers are more prevalent among households with assets exceeding the estate tax filing threshold than for those below the threshold, and that the propensity to engage in this behavior increases as health deteriorates. By contrast, earlier researchers found little convincing evidence that Medicaid-induced transfers were widespread among current or likely nursing home patients. ${ }^{2}$ They also concluded that because the percentage of people who spent down to Medicaid eligibility after entering a nursing home was small, and because most patients who spent down did so within a few months, that the loss to Medicaid from this population was small. Moreover, Norton [1995] concluded that welfare aversion may dominate the transfer motive in elderly households.

However, most of these studies suffered from important data limitations that the dataset used for this study, the Study of Asset and Health Dynamics Among the Oldest Old (AHEAD), does not share. First, all of the aforementioned studies rely to some extent on data that was collected prior to the passage of the Medicare Catastrophic Coverage Act $[\mathrm{MCCA}]$ in 1988, which contained several provisions that might have increased asset transfers. The first wave of AHEAD was conducted in 1993, and thus also reflects changes in transfer behavior caused by MCCA. One of the changes made by MCCA curtailed the ability of married couples to protect assets simply by transferring them to the healthier spouse. Using AHEAD, Norton and Kumar [1998] find evidence that this change made it more likely that married individuals would spend-down to Medicaid eligibility after entering a nursing home. MCCA also increased from 24 to 30 months the period prior to admission during which asset transfers are scrutinized. Intrator, et al. [1996] noted that, as a result, transfers may have increased in the months immediately prior to its

2 See, for example, Adams et al. [1993], Short et al. [1992], Sloan and Shayne [1993], and Branch et al. [1988]. 
enactment. Secondly, AHEAD is nationally representative of the non-institutionalized elderly population and contains specific information about recent financial transfers to children. By contrast, most of the earlier studies relied on data from surveys that focused solely on either institutionalized populations or a population where individuals were already experiencing a substantial decline in their health status. Finally, none of the earlier surveys asked directly about asset transfers, while AHEAD asked about gifts to children and grandchildren during the previous year.

Most importantly for this paper, however, AHEAD contains the respondents' selfassessed (subjective) probability of using a nursing home in the next five years. Because of statutory restrictions on transfers within the 36 months prior to entering a nursing home, planning for Medicaid eligibility entails acting on the expectation that a nursing home stay will occur. Therefore, the subjective assessment of the probability of using a nursing home in the medium-term future is precisely the variable of interest. If there is a behavioral effect associated with the Medicaid nursing home benefit, then, ceteris paribus, a higher subjective probability should lead to more transfers. In an otherwise unrelated paper, Bassett and Lumsdaine [2003] show positive and significant pairwise correlations between the subjective probability of: 1.) having medical costs exhaust your assets in the next five years, 2.) using a nursing home in the next five years, and 3.) giving financial assistance to family members in the next 10 years, which supports the notion that individuals understand that there is the potential to protect their assets from nursing home costs through asset transfers.

The results of this paper suggest that the subjective probability of nursing home entry is associated with a statistically significant increase in the incidence of transfers from elderly parents to their beneficiaries. Although the effect on the amount transferred per household is not significant, the increased incidence of transfers resulted in roughly $\$ 1$ 
billion per year in Medicaid-induced asset transfers during the early 1990s (compared with total Medicaid spending on nursing homes of about $\$ 32$ billion). However, not all of this amount ended up being a loss to Medicaid, because not everyone who transferred assets ended up entering a nursing home. The paper proceeds as follows: Section 2 describes the rules governing Medicaid eligibility and asset transfers. Section 3 presents the empirical strategy. Section 4 describes the data and presents some summary statistics. Section 5 reports the estimation results. Section 6 concludes.

\section{The Medicaid Nursing Home Benefit}

The income and asset thresholds for nursing home patients to obtain eligibility for Medicaid are determined by each state within the parameters of Federal guidelines; however, there are numerous commonalities across states. First, Medicaid requires recipients living in a nursing home to contribute almost all of their own income as a co-payment toward the cost of care. Second, asset and income limits are significantly more generous for married couples who have one member in a nursing home and one living in the community than they are for single individuals. Third, all of the equity in a primary residence is protected for as long as the patient states an intention to return, and longer if a spouse, dependent, or primary caregiver is living at that address. ${ }^{3}$ Finally, the District of Columbia and 35 states allow an applicant to subtract medical expenses from current income in order to meet the income threshold; households that qualify under these provisions are commonly referred to as "medically-needy."

\footnotetext{
3 States can technically include the value of a primary residence in the eligibility process, but there has been little enforcement of such provisions (Liu and Moon [1995]). Property used in operation of a business, the value of a car up to $\$ 4,500$, a small face value of life insurance, and a nominal amount that can be dedicated to funeral expenses are also exempt from the asset test.
} 
The conditions insure that not all households are able to qualify for Medicaid by making transfers. Let $C$ be the cost of nursing home care, and let $A$ be the amount of nonexempt net worth held by the household. Let $Y$ be the amount of nonbequeathable income flowing to the household (such as defined benefit pension payments, other private annuities, and social security). Let $L$ be the Medicaid eligibility limit for assets. Then there are three cases:

1) $Y>C$

These individuals must use their income stream to pay the entire cost of nursing home care and will never qualify for Medicaid's nursing home benefit.

2) $A<L$

Transfers have no effect on Medicaid eligibility for individuals that already have assets below the level required to qualify for Medicaid's nursing home benefit.

3) $Y<C$ and $A>L$

In this case, individuals would need to contribute to the cost of nursing home care from the income earned on their assets or by spending down the assets themselves, and the Medicaid nursing home benefit might motivate transfers. ${ }^{4}$

\section{Empirical Strategy}

Consider the decision faced by an elderly parent who holds a significant stock of assets, but receives insufficient nonbequeathable income to cover the costs of nursing home care. In the event that the parent enters a nursing home without transferring any assets she

\footnotetext{
${ }^{4}$ Of 6,047 households in Wave 1 of AHEAD, 297 are missing the necessary financial information to determine their status. Assuming $C=\$ 30,000$ (approximating the annual cost of a nursing home in 1993)+the annual income threshold that nursing home residents and their spouses can retain based on individual state income limits, and assigning $L$ based on individual state asset limits: 110 observations correspond to case (1), 2,154 to case (2), and the rest fall into case (3).
} 
will have to self-finance the costs until she becomes poor enough to qualify for Medicaid. However, if the parent transfers a sufficient amount of assets to her children prior to entering the nursing home, then Medicaid will cover the nursing home costs that are in excess of her current income. Thus, if the parent faces a positive probability of entering a nursing home and derives utility from the consumption of her children in addition to her own consumption, then she may decide to smooth intergenerational consumption through asset transfers.

Assume that parents derive utility from consumption of a composite good (consisting of both consumer goods and medical services) and the value of assets that they transfer to their children. ${ }^{5}$ The parent is initially living in the community but faces some positive probability of becoming sufficiently disabled as to need to enter a nursing home, denoted $\pi_{D} \cdot{ }^{6}$

As shown in Appendix 1, the optimal value of transfers can be written as the implicit function:

$$
T^{*}\left(\pi_{D}, A, X, L\right)
$$

Where $A$ and $L$ are defined as in Section II, and $X$ is a vector of exogenous demographic characteristics. When $T^{*}>0$ parents make a transfer to their children, otherwise assume that we observe no transfers between the parent and children. Let $z$ be an indicator variable that takes the value of 1 when we observe a transfer and 0 otherwise. Assume further that $T^{*}(\cdot)$ can be approximated by a linear function, $Q \beta$, where the vector $Q$ includes $X, A, C$ and $\pi_{D}$ and $\beta$ is the vector of coefficients.

5 The assumption of a composite good maintains the problem as two-dimensional in order to focus on transfers.

${ }^{6}$ The assumption that healthy individuals do not enter nursing facilities reflects the requirement that nursing home residents meet a minimum standard of disability. 


$$
\begin{gathered}
T^{*}=Q \beta+\mu \\
\mu \sim N\left(0, \sigma_{\mu}^{2}\right) \\
z=1 \text { if } T^{*}>0 \\
z=0 \text { if } T^{*} \leq 0
\end{gathered}
$$

Then it follows that the likelihood of making a transfer is $\mathrm{P}\left(T^{*}>0\right)=\mathrm{P}(Q \beta>-\mu)$, and with normally distributed errors, the appropriate model is a probit model. The level of transfers for households that made a transfer is then estimated by ordinary least squares with a mills ratio correction.

\section{The Data}

AHEAD is a nationally representative sample of 6,047 households where the household head was a non-institutionalized individual age 70 or older at the time of the baseline interview in 1993; their spouses were interviewed regardless of age. I deleted all households that classified their status as living together but not married, as well as those that were missing data for any variables used in the regression analysis. I also deleted the residents of one state in which fewer than 5 households were interviewed, resulting in a final sample of 3,393 households.

The average age of household heads in the sample is 76 years old, and 39 percent of the household heads are married. The median total income of the households in the sample is $\$ 19,200$. The median net worth is $\$ 102,000$, but 76 percent of households in the sample own homes, making median non-housing net worth $\$ 23,000$. Hence, for a single individual in 1993 with sample median net worth and income, a one-year stay in an average price nursing home $(\$ 30,000)$ would exhaust all of his income for that year and about half of his non-housing net worth.

Table 2 defines the variables used in the subsequent regression analyses and details 
some summary statistics. Although the discussion centers on the subjective probability of entering a nursing home, other variables are also related to the Medicaid nursing home benefit. Following Bassett (1999) I constructed the state-specific Medicaid asset and income limits faced by each household, as well as indicator variables for households that resided in states that had medically-needy statutes. To control for the supply of nursing home services, I included a state specific measure of the number of nursing home beds per 1,000 individuals over the age of 65 . Marital status has important implications for transfer behavior and affects Medicaid eligibility thresholds; therefore, both marital status and various spousal characteristics are included separately in the regression.

In addition to the possible effects of Medicaid planning, parents transfer assets to their children for other reasons for which the breadth of data in AHEAD allows the researcher to control. The strategic bequest literature hypothesizes that when there is more than one potential beneficiary, parents can use inter-vivos transfers to elicit desirable behavior from their children (Bernheim et al., [1985]). McGarry and Schoeni [1995] show that the financial and family status of children is important in determining parental transfers. If the respondent or spouse have living parents they may face additional financial or caregiving responsibilities. Hill, Soldo, and Li [1993] show that volunteer work represents a good proxy variable for the parents' generosity level. Variables to control for each of these reasons are included in the regression.

The subjective probabilities that the respondent and spouse will live an additional 10 to 15 years are included in each regression. For instance, a respondent who was between ages 70 and 74 was asked the probability of living to age 85 , while a respondent who was between ages 75 and 79 was asked the probability of living to age 90, etc. These variables are potentially useful in this analysis because they might capture additional information about the underlying health status of the household members. Moreover, households in 
which the residents believed that they were close to death might make transfers that are motivated by estate tax avoidance (Bernheim et al. [2001]; Feinstein and Ho [2000]).

\section{Expectations of Nursing Home Use}

To answer questions concerning individuals' expectations of future events, AHEAD instructs respondents to, "...[G]ive a number between 0 and 100, where 0 means you think there is absolutely no chance, and 100 means that you think the event is certain to happen." The question related to nursing home use was:

"Of course nobody wants to go to a nursing home, but sometimes it becomes necessary. What do you think are the chances that you will move to a nursing home in the next five years?"

Out of the original 8,222 respondents, 6,362 answered with a valid response, while 761 said they did not know, 239 refused and 860 proxy interviewees were not asked the question. ${ }^{7}$

Among those that answered the question in the survey, the average subjective probability of using a nursing home in the next five years was 14 percent. As shown in chart 1, almost 60 percent of AHEAD respondents report that there is absolutely no chance that they will enter a nursing home in the next 5 years. Another 20 percent report only a 1 percent to 25 percent chance of entering a nursing home in the next 5 years. Conversely, only 5 percent feel that they have greater than a 50 percent probability, while an additional 13 percent rate their odds of entering a nursing home as exactly 50 percent.

The central focus of this paper is not to test whether individuals can correctly forecast their entry into a nursing home, or even whether their expectations are rational, but rather whether people are behaving in a manner that is consistent with their stated

7 Proxy interviews were conducted when there was a language barrier, when one spouse refused to participate in the study, or when the sampled individual was unable to respond for health reasons. The majority of the proxy interviews were conducted for health reasons. There is some evidence that there is a selection effect between those who answered and those who did not. However, sensitivity analysis indicates that the conclusions of this paper are unaffected by excluding the households without valid responses. 
expectations. Nonetheless, the mean subjective probability of using a nursing home of AHEAD respondents is not inconsistent with other data sources (Dick et al. [1994]; Kemper and Murtaugh [1991]; Headen [1993]). In addition, other authors have shown that the responses seem to be correctly incorporating factors known to determine nursing home use (Holden et al. [1997]; Lindrooth et al. [2000]).

\section{The Transfer Decision}

AHEAD asks the following question on inter-vivos transfers:

"In the last 12 months did you [or your (husband / wife / partner)] give financial help or gifts of $\$ 500$ or more to any child or grandchild (or to any other person)."

The distribution of transfers to children and to grandchildren is shown in chart 2. Although many gifts were relatively small, those are not immaterial given the median nonhousing net worth of the sample. In addition, the sample includes a not insignificant fraction of gifts that were in excess of $\$ 5,000$. Overall, 29 percent of the sample gave a gift in excess of $\$ 500$, and the average (median) gift conditional on having made a gift in excess of $\$ 500$, was about $\$ 5,000(\$ 2,000)$.

Table 3 reports the fraction of households making a transfer and the average amount of transfers for different categorical values of the households' likelihood of using a nursing home. ${ }^{8}$ For unmarried respondents, the fraction that made a transfer rose somewhat as the stated probability of using a nursing home increased from low to moderate, while the largest transfers were made by individuals that had very low, but nonzero, probabilities of entering a nursing home. For married households, the table is best understood by reading diagonally from the top left corner to the lower right corner. The incidence of transfers

\footnotetext{
8 For married couples, the "respondent" is the person that was designated by the questioner as the more financially astute member of the couple, and almost always was the male.
} 
when neither member considered using a nursing home at all likely was about 34 percent. The average incidence of giving a gift for households where at least one member reports a probability of using a nursing home between 3 percent and 19 percent, and neither spouse reports a probability of 20 percent or more, is 37 percent. Meanwhile, almost 50 percent of the households in which both spouses report a probability of using a nursing home that is greater than 20 percent (the four results in the lower right corner) made gifts during the previous 12 months.

The relationship between the probability of using a nursing home and the amount of assets transferred was very loose and could be nonlinear. Married households in which at least one spouse had a moderate probability of using a nursing home tended to transfer more assets than those in which both the respondent and the spouse reported a zero probability, and also more than households in which both members had a very high probability. One explanation for the lower level of gifts at very high probabilities is that as nursing home use becomes imminent, ineligibility statutes hinder the household's ability to shield assets through large transfers.

\section{Econometric Results}

The key independent variable discussed in sections 3 and 4 is the probability of becoming sufficiently disabled to qualify for nursing home care, $\pi_{D}$. One interpretation of the responses to the question in AHEAD that elicits the subjective probability of using a nursing home in the next 5 years (denoted $\mathrm{P}(\mathrm{NH})$ from here on) is that they represents the product of $\pi_{D}$ and the probability of choosing to live in a nursing home conditional on becoming disabled, rather than only the exogenous component, $\pi_{D}$. However, the introduction to the question asked by AHEAD interviewers, "Of course nobody wants to go to a nursing home, but sometimes it becomes necessary...," may suggest to the respondents that 
they view entry into a nursing home not as a choice, but as the result of a catastrophic (exogenous) event. The tone of the question should also help the respondents to distinguish between the probability of being forced to move into a skilled nursing facility and the probability of choosing to reside in an assisted living community, which have become popular among some elderly. Cutler and Sheiner [1993] report that only 7 percent of respondents to the National Long-Term Care Survey disagreed with the statement, "People go to nursing homes only when there is no other place to live," providing empirical support for the stricter interpretation of the AHEAD question. Moreover, in most cases, individuals must exhibit multiple functional impairments before they can even apply for admittance to a skilled nursing facility, and those functional impairments are also reasonably considered exogenous. Thus, I proceed by assuming that $\mathrm{P}(\mathrm{NH})$ does, in fact, represent only the individuals' subjective assessments of $\pi_{D}$.

Current income and wealth are also, to varying degrees, endogenously determined by the transfer decision. Therefore, I use a set of variables that are more plausibly exogenous to control for the financial situation of the household. Education is widely accepted to be highly correlated with lifetime income and wealth, and education levels for AHEAD respondents were determined by decisions made many years prior to the survey. Thus, the regressions contain three indicator variables for the highest education level obtained by the respondent and a corresponding set of variables for the spouse (or former spouse if widowed or divorced). Defined benefit pension income and social security income not only are correlated with the household's permanent income and wealth, but also very highly correlated with current income. Those income streams are more plausibly exogenous than total current income, because they have largely been pre-determined by decisions made about workforce participation years earlier, and, as noted, cannot be transferred to others for the purpose of facilitating Medicaid eligibility. The regressions also contain a variable 
for whether the household members' longest held occupation was technical, professional or managerial in nature, which will reflect the higher lifetime earnings typically associated with those job descriptions.

Table 4 presents the results of probit models in which the dependent variable is equal to one if the household made a transfer of $\$ 500$ or more in the past 12 months, and zero otherwise. The table shows marginal effects as well as the coefficients and standard errors of the independent variables on the probability of making a transfer. The coefficients on the amount of pension, annuity, and social security income are all highly statistically significant and positive across all specifications, as are the indicator variables for being in a technical, professional, or managerial occupation. Those results likely reflect the obvious association between the ability to give financial gifts and the adequacy of current income and wealth.

The variables denoting the highest levels of education completed by the respondent also have a positive and statistically significant effect on the probability of giving a gift in each specification. The effect of the education level of the current or ex-spouse is also positive, and the variables are jointly significant at traditionally accepted confidence levels. Moreover, the marginal effects of education levels are fairly large in magnitude and increase as the level of education rises, likely owing, in large part, to the high correlations of education with income and wealth and of income and wealth with financial transfers. Two other results are also consistent with stylized facts about the distribution of income and wealth: Single male respondents were more likely to make gifts than single females, and white households were more likely to transfer assets than minority households.

The number of children was a positive and statistically significant determinant of gifts, as predicted by both the altruism and the strategic bequest literature. Households that had no children were about 12 percent less likely to have given gifts in the previous year. 
The marginal effect of additional children -calculated as the increase in the probability of making a transfer resulting from a one-standard-deviation increase in the independent variable-was almost 4 percent. In addition, the propensity to make financial transfers was significantly reduced if those children were already married. This result is consistent with parental altruism, because married children are more likely to be financially secure, on average, and less likely to need assistance. By the same token, it may be inconsistent with the strategic bequest hypothesis, because strategically motivated children would require higher levels of gifts to provide the same level of attention to the parents' needs as their own financial condition improved.

In addition, the regressions control for inter-state variation in Medicaid nursing home eligibility requirements. The coefficients on the four variables that control for inter-state variation in Medicaid eligibility-income limits, asset limits, medically-needy status, and the supply of nursing home beds in the state of residence-have the expected signs; however, they are neither individually nor jointly statistically significant at traditional confidence levels.

As shown in panel 1, when the respondent's and the spouse's probability of using a nursing home are entered alone, without interaction or nonlinear effects, the coefficients on both are positive and individually statistically significant. Evaluated at the mean of all the other variables, a one standard deviation rise in the respondent's or spouse's subjective probability of nursing home use corresponds to almost a 2 percentage point greater likelihood of making a transfer. Thus, after controlling for income and wealth, as well as a myriad of nonpecuniary factors affecting transfer behavior, including health and generosity, there appears to be a meaningful positive correlation between $\mathrm{P}(\mathrm{NH})$ and gift giving.

In panel 2, we add quadratic effects of $\mathrm{P}(\mathrm{NH})$ : The coefficients on the squared terms 
are negative while the coefficients on the linear terms are positive, as the results of table 1 suggested for unmarried respondents. The coefficients on the respondent's nursing home probability suggest that the effect of $\mathrm{P}(\mathrm{NH})$ on the likelihood of making a financial transfer is maximized when $\mathrm{P}(\mathrm{NH})$ reaches about 75 percent. At higher levels the probability recedes a bit, but the marginal effect of $\mathrm{P}(\mathrm{NH})$ on gift giving is always positive. At $\mathrm{P}(\mathrm{NH})$ of 100 percent the likelihood of making a transfer, is equal to the likelihood when $\mathrm{P}(\mathrm{NH})$ is around 50 percent. Although none of the four variables are individually statistically significant in this specification, the likelihood ratio test statitic for all four variables is significant at the .05 confidence level. The likelihood ratio test statistic for the quadratic terms only, however, has a p-value of just 0.87 .

The specification shown in panel 3 uses indicator variables for respondents' and spouses' $\mathrm{P}(\mathrm{NH})$ between 20 percent and 59 percent and for $\mathrm{P}(\mathrm{NH})$ greater than or equal to 60 percent. The results are consistent with the use of the continuous variable, but the marginal effects are much larger, especially for the spouse variables. Households in which the respondent has a $\mathrm{P}(\mathrm{NH})$ greater than 60 are more than 5 percentage points more likely to make a gift, while the marginal effect on transfers is 13 percent when the spouse of a married couple has a very high $\mathrm{P}(\mathrm{NH})$. Taken together, the results in the first three panels confirm the observations made based on Table 3 after controlling for income and other factors affecting transfer behavior.

As noted above, education has a significant and large positive effect of on the incidence of transfers, and that effect arises even though other controls for income and wealth are included in the regression. This could be evidence that people with a higher level of education are better able to understand, and thus are more likely to take advantage of, the loopholes in the Medicaid nursing home benefit. In panel 4, the interaction of $\mathrm{P}(\mathrm{NH})$ for the respondent and the spouse with an indicator variable for whether at least one 
member of the household completed college supports this interpretation. The coefficients on the interaction terms are positive, and the four variables controlling for $\mathrm{P}(\mathrm{NH})$ in that specification are jointly significant at the 5 percent confidence level. The positive effects on transfers of both income and education also may be due, in part, to the fact that individuals with higher income levels and substantial assets to protect are more likely to receive professional estate planning advice.

It is also worth emphasizing that the effects of the variables controlling for the probability of using a nursing home are observed even though the regressions contain other controls for variation in the health of household members. The coefficient estimates on the expected probabilities of living 10 to 15 more years are never statistically significant at traditional confidence levels. However, the probability of living significantly longer is negatively correlated with the incidence of financial transfers in each of the models, which would be consistent with households that were engaging in estate planning. The coefficients on the dummy variables controlling for "bad" health of the respondent and spouse are negative and significant at usual confidence levels. This result is consistent with the idea that households in which one or more members are experiencing poor health will conserve resources to pay for medical care, conditional on the probability of entering a nursing home. Indeed, the marginal effect of an increase in the respondent's or spouse's $\mathrm{P}(\mathrm{NH})$ are larger when these controls for health status are included in the regression than when they are not (not shown). Thus, as noted above, the difference between the actual probability of using a nursing home, which is captured, in part, by the health variables and by the variables indicating life expectancy, and the subjective probability, which for some people might have a (large) component that is independent of health, is an important distinction. Households are acting in a manner that is consistent with their perceived probability of using a nursing home, even if that perceived probability is over- 
or under-estimated.

Table 5 reports the results of OLS regressions for the amount of transfers for the sample of households that gave gifts totaling $\$ 500$ or more in the prior 12 months. The dependent variable is equal to the natural $\log$ of total gifts. The mills ratio from the corresponding regression in panel 1 is included to account for the probability that the household made a transfer. Identification relies on the nonlinear transformation of the probit coefficients.

In contrast to the importance of $\mathrm{P}(\mathrm{NH})$ in determining the probability of making a transfer, these results indicate very little correlation between $\mathrm{P}(\mathrm{NH})$ and the amount transferred. In the middle panel, $\mathrm{P}(\mathrm{NH})$ for the respondent and spouse is entered both linearly and with a quadratic term, because Table 3 suggested that a higher perceived probability of using a nursing home initially increases and then decreases the amount transferred. The coefficients on the linear terms for $\mathrm{P}(\mathrm{NH})$ are both positive, and the coefficients on the quadratic terms are negative, providing some additional support for the conclusions drawn from Table 1 . However, the estimated coefficients are each individually insignificant at generally accepted confidence levels, and the variables are also insignificant when considered jointly. Using indicator variables for moderate and for high values of $\mathrm{P}(\mathrm{NH})$ produces results that are consistent with the other specifications and with Table 3 , but the variables are jointly insignificant at traditional confidence levels.

The size of gifts given is, as might be expected, largely determined by the variables that control for income and wealth. Interestingly, however, the coefficient on pension income is negative and signficant at the 5 percent confidence level. This result could partially reflect that fact that pension income must be used as a co-payment to the nursing home before Medicaid coverage begins, thus households with high levels of such nontransferable income might make fewer Medicaid-induced asset transfers. Similarly, married 
households tend to be more financially secure than single elderly, but married people transfer fewer assets than nonmarried households. In part, this could reflect the higher asset eligibility thresholds for married couples than for singles, a conclusion supported by the marginally significant positive coefficient on asset limits in the regressions.

\section{Fiscal Implications}

Previous research contends that transfers, even if they occur, are likely to represent only a small fraction of Medicaid spending. In 1995, there were 21.4 million households headed by someone age 65 or older (U.S. Bureau of the Census, Current Population Reports, P25-119). In the full sample of AHEAD respondents, the weighted fraction of households that face at least some incentive to transfer assets because of the Medicaid nursing home benefit is 60.1 percent. However, it is likely that households with very high levels of nonexempt financial assets would be unlikely to make transfers for the purpose of becoming eligibile for Medicaid. After removing all AHEAD households with non-exempt net worth greater than $\$ 500,000$, that fraction is reduced to 57.2 percent. If this percentage remains representative of the population over 65 , then there are close to 12.2 million households that might transfer assets for this purpose.

Of the 3,288 largely middle-class elderly households in the AHEAD study, about 36 percent made transfers during the 12 months preceding the first wave of AHEAD, and those gifts averaged almost $\$ 5,000$. If the over-65 population transfers assets at the same rate as the sample, then those 12.2 million households would make $\$ 21.5$ billion in transfers. Using the estimates from the fourth column of Table 3, the average probability

of making a transfer using the sample distribution of $\mathrm{P}(\mathrm{NH})$ is 1.8 percent greater than the average probability of making a transfer when setting $\mathrm{P}(\mathrm{NH})=0$ for all households. This implies that about 220,000 households make a transfer largely because of the incentives provided by Medicaid eligibility rules. Given the lack of a significant effect of $\mathrm{P}(\mathrm{NH})$ on 
the amount of assets transfered conditional on having made a transfer, it is reasonable to assume that those households would have given away the same amount as the average household in the middle-class sample from AHEAD. Thus, the estimated total amount of Medicaid-induced asset transfers is approximately $\$ 1$ billion per year, or about 3 percent of Medicaid nursing home expenditures in 1993.

Of course, not all of these transfers represent a loss to the Medicaid system. Some of these individuals will never enter a nursing home. Kemper and Murtaugh (1991) estimate that 43 percent of individuals who reach age 65 will spend some time in a nursing home. Assuming independence across married couples and using the fractions of married and single households over age 65 in the U.S. population, this implies that only 53.6 percent of households will have at least one member enter a nursing home. In addition, some of these stays are likely to be short-term stays for acute care, which is covered by Medicare, and other stays will end prior to spend-down even after correctly accounting for transfers. Thus, it is unclear how much of the $\$ 1$ billion per year estimate of total transfers by those over age 65 should be counted as a loss to Medicaid.

In any case, the cost to taxpayers from these strategies is poised to escalate. The population over age 65 is projected to increase steadily for several decades (U.S. Bureau of the Census, Current Population Reports, P25-119), so the number of households for whom asset transfers are beneficial could continue to grow. Moreover, workers today are far less likely than their parents to have a traditional annuity-like defined benefit pension plan and more likely to have a defined contribution plan. Whereas the income stream derived from a defined benefit pension is non-transferable and must be paid to the nursing home to offset Medicaid payments, defined contribution money could be transferred to beneficiaries prior to a nursing home stay just like any other financial asset. In recognition of the rising potential for Medicaid planning, some states have recently begun to crack 
down on transfers and to enforce their claim on the principal residence of unmarried patients at the time of their death.

\section{Conclusion}

This study suggests that many individuals put some odds on future nursing home use, and thus are more likely to make transfers as a result of Medicaid rules. The resulting rise in transfers probably causes at least a modest increase in Medicaid expenditures. Using a nationally representative study of community resident elderly, I have shown that households and individuals with a higher subjective probability of future nursing home use are more likely to have made inter-vivos transfers in the past 12 months. There is also some evidence of a nonlinear relationship between the perceived probability of using a nursing home and asset transfers, with the largest transfers occurring at moderate levels of $\mathrm{P}(\mathrm{NH})$, before falling off when nuring home use becomes more certain. Such a pattern is consistent with the effectiveness of laws designed to discourage Medicaid planning behavior. This pattern also helps to reconcile the results of this paper with those

of previous researchers who concluded that asset transfers among disabled populations were small: Previous researchers were studying populations that were likely similar to those in AHEAD with very high $\mathrm{P}(\mathrm{NH})$. 


\section{APPENDIX 1}

Two-Period Model of Consumption and Transfers

An individual derives utility from their consumption in a given health state and asset transfers. The individual can be in one of three health states: Healthy and living in the community $(\mathrm{H})$, disabled and living in the community $(\mathrm{D})$, or disabled and living in a nursing home (I). The utility function for a given heath status is:

$$
U\left(C_{j}, T ; X, \epsilon\right)
$$

where:

$$
\begin{aligned}
& j \in[I, D, H] \\
& U_{1}(\cdot), U_{2}(\cdot)>0 ; U_{11}(\cdot), U_{22}(\cdot)<0 ; \text { and } U_{21}=0 \\
& \epsilon_{j} \sim(0, \delta) ; \\
& A=\text { amount of bequeathable assets; } \\
& C_{j}=\text { consumption in state } \mathrm{j} ; \\
& T=\text { transfers; } \\
& X=\text { a vector of demographic variables. }
\end{aligned}
$$

The vector of exogenous variables, $\mathrm{X}$, contains some components that are unobserved to the researcher, but known to the individual, such as unobserved heterogeneity in tastes. The error term, $\epsilon$, represents quantities unknown to both the researcher and the decision 
maker, such as uncertain quality of nursing home care.

Assume that the household has both Medicare and a supplemental insurance policy that combined will cover all conventional medical costs, but that the cost of nursing home care is covered only by Medicaid. Therefore, the composite good will be more expensive in the nursing home state if the household is not eligible for Medicaid (denoted as $\mathrm{k}=\mathrm{N}$ ), and less expensive in the nursing home state if the household is eligible for Medicaid $(\mathrm{k}=\mathrm{Y})$. Let the parameter, $p_{j, k}$, represent the price of the composite good in state $j$ with Medicaid eligibility status $k$, where:

$$
p_{H}=p_{D}=1, p_{I, N}=s>1 \text { and } p_{I, Y}=w<1 .
$$

Thus, $C_{H}=C_{D}=(A-T)$ and $C_{I, k}=\frac{(A-T)}{p_{I, k}} \cdot{ }^{9}$ The household's decision is:

$$
\begin{gathered}
\max \\
\mathrm{T} \\
\\
\\
\text { s. t. } \\
T+p_{j, k} C_{j} \leq A
\end{gathered}
$$

where $\pi_{D}$ is the probability of becoming disabled and $U_{j}$ represents utility with consumption $C_{j}$.

In order to make the objective function continuous, write the probability of entering a nursing home, conditional on being disabled, as:

$$
\pi_{I}(\cdot)=\pi_{I}\left(V_{I}-V_{H}\right) \quad \frac{\partial \pi_{I}}{\partial T}>0
$$

where $V_{j}, j \in[I, D, H]$, indicates the non-stochastic part of utility $U\left(C_{j},{ }^{\circ}\right)$. The unconditional probability of entering a nursing home, $\pi_{N H}$, is equal to the product $\pi_{D} \pi_{I}$.

\footnotetext{
9 The qualitative conclusions drawn from the model are unaffected if the assumption $p_{H}=p_{D}$ is relaxed to $p_{H}<p_{D}$.
} 
Conversely, the unconditional probability of living in the community, $\pi_{H}$, is equal to $\left(1-\pi_{N H}\right)$. Combining equations 2 and 3 , and substituting the constraint, yields the objective function:

$$
\underset{\mathrm{T}}{\max } \quad Z=\left(1-\pi_{D}\right) U_{H}+\pi_{D}\left[\pi_{I} U_{I}+\left(1-\pi_{I}\right) U_{D}\right]
$$

which reduces to:

$$
\underset{\mathrm{T}}{\max } \quad Z=\left(1-\pi_{D} \pi_{I}\right) U(A-T, T ; \cdot)+\pi_{D} \pi_{I} U\left(\frac{(A-T)}{p_{I, k}}, T ; \cdot\right) .
$$

Following Moffitt [1983], the easiest way to portray the solution is to first solve for the optimal value of $T$ while holding Medicaid participation constant, and then determining the utility maximizing value of $k$. Differentiating (4) with respect to $T$, while holding $p_{I, k}$ constant, gives:

$$
F=U_{2}(\cdot, T ; \cdot)-\left[\left(1-\pi_{D} \pi_{I}\right) U_{1}\left(C_{H}, \cdot\right)+\frac{\pi_{I} \pi_{D}}{p_{I, k}} U_{1}\left(C_{I}, \cdot\right)\right]+\pi_{D} \frac{\partial \pi_{I}}{\partial T}\left(V_{I}-V_{H}\right)=0 .
$$

The first and second terms represent the marginal utility from transfers in the community and nursing home states. The third term represents the marginal utility from changing the probability of entering a nursing home.

The solution to equation 5 gives the optimal amount of transfers, $T^{*}$, as a function of the exogenous variables and $p_{I, k}$. Let this solution be defined implicitly by:

$$
T^{*}\left(\pi_{D}, A, X, p_{I, k}\right)
$$

Thus, there will be two different demand functions for transfers. In order to determine the value of $k$, we must compare the expected value of the indirect utility function under $p_{I, Y}$ and $p_{I, N}$ :

$$
W^{*}=V\left(T^{*}\left(p_{I}=w, \cdot\right), \cdot\right)-V\left(T^{*}\left(p_{I}=s, \cdot\right), \cdot\right)
$$


If $W^{*}>0$ then the individual will choose to make transfers $T^{*}\left(\pi_{D}, A, X, w\right)$, otherwise she will make transfers $T^{*}\left(\pi_{D}, A, X, s\right)$.

Such a complicated dynamic process is difficult to solve analytically. However, one can incorporate a probability of qualifying for Medicaid into the single period framework. The probability will be dependent upon the initial level of assets, transfers, and characteristics of the Medicaid system such as asset limits and the difference between $w$ and $s$. Define that probability to be:

$$
\pi_{M}=\pi_{M}(A, T, L)
$$

where $L$ represents the characteristics of the Medicaid system. ${ }^{10}$ Then the objective function (4) can be re-written as:

$\max _{\mathrm{T}} Z=\left(1-\pi_{D} \pi_{I}\right) U(A-T, T ; \cdot)+\pi_{D} \pi_{I}\left[\pi_{M} U\left(\frac{(A-T)}{p_{w}}, T ; \cdot\right)+\left(1-\pi_{M}\right) U\left(\frac{(A-T)}{p_{s}}, T ; \cdot\right)\right.$.

The optimal value of transfers can be shown, as before, to be the implicit function:

$$
T^{*}\left(\pi_{D}, A, X, L\right)
$$

10 This could again be expressed as a function of the difference in expected utilities when qualifying for Medicaid as opposed to not qualifying. 


\section{BIBLIOGRAPHY}

Adams, E. Kathleen, Brian O. Burwell, and Mark R. Meiners. "Asset Spend-Down in Nursing Homes: Methods and Insights." Medical Care, January 1993, 31(1), 1-23.

Bassett, William F. "Medicaid, Asset Transfers, and Expectations of the Elderly." Providence, RI: Brown University, 1999.

Bassett, William F. and Robin Lumsdaine. "Outlook, Outcomes, and Optimism." mimeo, Federal Reserve Board, 2003.

Bernheim, B.D., A. Schleifer, and Lawrence Summers. "The Strategic Bequest Motive." Journal of Political Economy, 1985, 93(6), 1045-79.

Bernheim, B.D., Robert J. Lemke, and John Karl Scholz. "Do Estate and Gift Taxes Affect the Timing of Private Transfers?" NBER Working Paper W8333 June 2001.

Branch, L. G., D.J. Friedman, M. A. Cohen, N. Smith, and E. Socholitzky. "Impoverishing the Elderly: A Case Study of the Financial Risk of Spend-Down Among Massachusetts Elderly People." Gerontologist, 1988, 28() 648-51.

Cutler, David, M., and Louise M. Sheiner. "Policy Options for Long-Term Care." in David A. Wise, ed., Studies in the Economics of Aging. Chicago, IL: University of Chicago Press, 1994, 365-94.

Dick, Andrew, Alan M. Garber, and Thomas A. MaCurdy. "Forcasting Nursing Home Utilization of Elderly Americans." in David A. Wise, ed., Studies in the Economics of Aging. Chicago, IL: University of Chicago Press, 1994, 395-434.

Feinstein, Jonathan S., and Chih-Chin Ho, "Elderly Asset Management and Health: An Empirical Analysis." NBER Working Paper \#7814 July 2000.

Gruber, Jonathan, and Aaron Yelowitz. "Public Health Insurance and Private Savings." Journal of Political Economy, 1999, 107(6), 1249-74.

Headen, Alvin E. "Economic Disability and Health Determinants of the Hazard of Nursing Home Entry." Journal of Human Resources, 1993, 28(1), 80-108.

Hill, Martha S., Beth J. Soldo, and Wei Li. "Intergenerational Transfers and Labor Supply: Preliminary Evidence from the HRS." Heath and Retirement Study Working Paper Series, 94-009, November 1993.

Holden, Karen, Timothy McBride, and Maria Perozek. "Expectations of Nursing Home Use in the Health and Retirement Study: The Role of Gender, Health, and Family Characteristics." Journal of Gerontology:Social Sciences, 1997, 52B(5), S240-51.

Hubbard, R. Glenn, Jonathan Skinner, Stephen P.Zeldes. "Precautionary Saving and 
Social Insurance" Journal of Political Economy, April 1995, 103(2), 360-99

Intrator, Orna, Vince Mor, Marilyn A. Hines, Tony Lancaster, Linda L. Laliberte, and Walter Freiberger. "Effect of the Medicare Catastrophic Coverage Act on Payer Source Changes Among Nursing Home Residents." Inquiry, Spring 1996, 33(1), 42-52.

Kemper, P., and C.M. Murtaugh. "Lifetime Use of Nursing Home Care." New England Journal of Medicine, 1991, 324(9), 595-600.

Lindrooth, Richard C., Thomas J. Hoerger, and Edward C. Norton. "Expectations among the Elderly about Nursing Home Entry" Health Services Research, December 2000, $35(5), 1181-1202$

Liu, Korbin and Marilyn Moon. "Recovering Hidden Assets: The Magic Bullet for Medicaid Savings?" The Urban Institute Policy Bites \#23, September 1995.

McGarry, Kathleen and Robert F. Schoeni. "Transfer Behavior in the Health and Retirement Study." Journal of Human Resources, 1995, XXX:Supplement, S184-S222.

MetLife. "MetLife Market Survey on Nursing Home and Home Care Costs 2002." MetLife, April 2002.

Norton, Edward C. "Elderly Assets, Medicaid Policy, and Spend-Down in Nursing Homes.' Review of Income and Wealth, September 1995, 41(3), 309-29.

Norton, Edward C., and Virender Kumar. "The Long-Run Effect of the Medicare Catastrophic Coverage Act" Inquiry, Summer 2000, 37(2), 173-87.

Powers, Elizabeth T., "Does Means-Testing Welfare Discourage Saving? Evidence from a Change in AFDC Policy in the United States." Journal of Public Economics, April 1998, 68(1), 33-53.

Short, Pamela Farley, Peter Kemper, Llewellyn J. Cornelius, and Daniel C. Walden. "Public and Private Responsibility for Financing Nursing Home Care: The Effect of Medicaid Asset Spend-down." Milbank Quarterly, 1992, 70(2), 277-97.

Sloan, Frank A. and May Shayne. "Long-Term Care, Medicaid, and Impoverishment of the Elderly." Milbank Quarterly, 1993, 71(4), 575-99. 
Chart 1

Probability of Using a Nursing Home

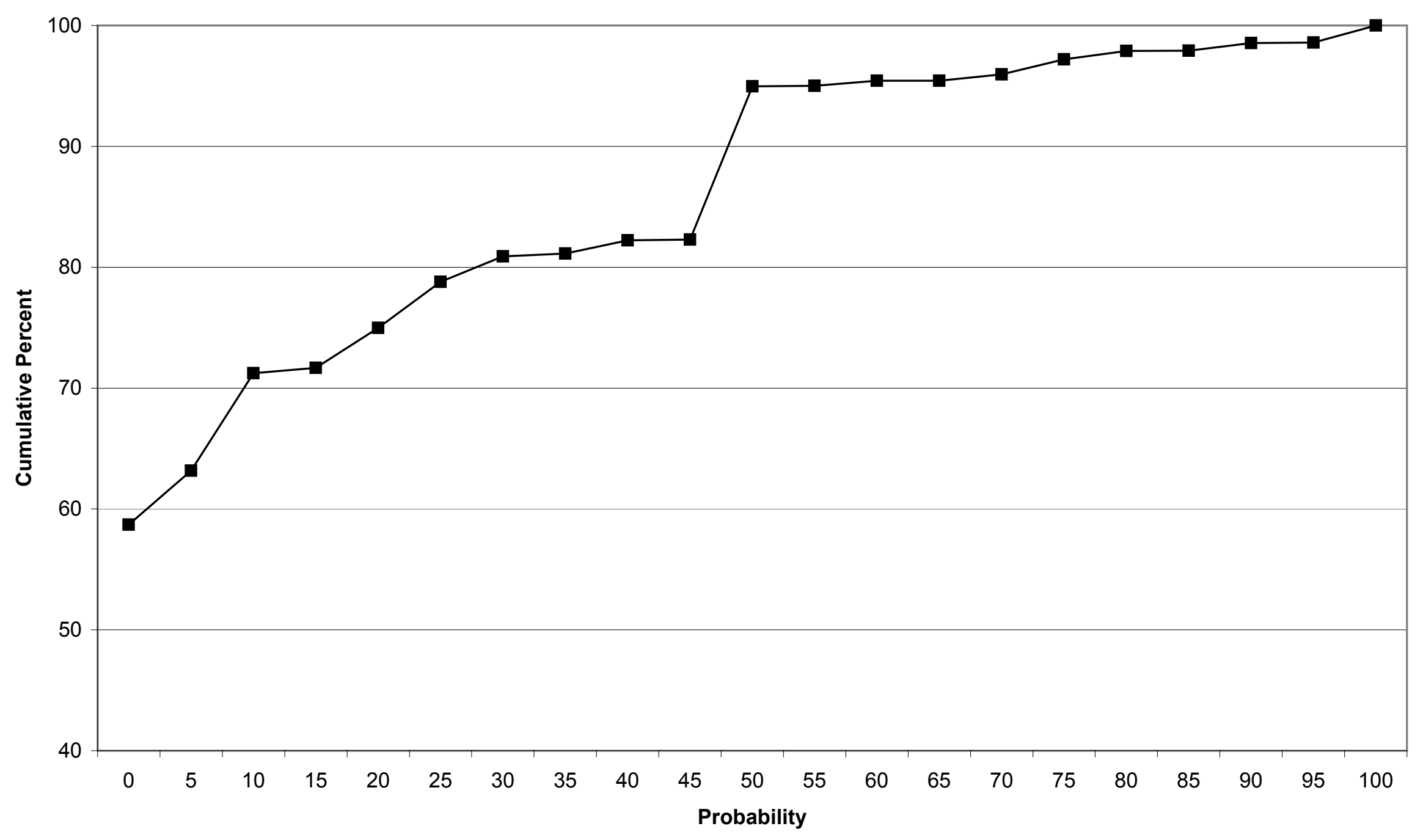


Chart 2

Distribution of Gifts Given to Others

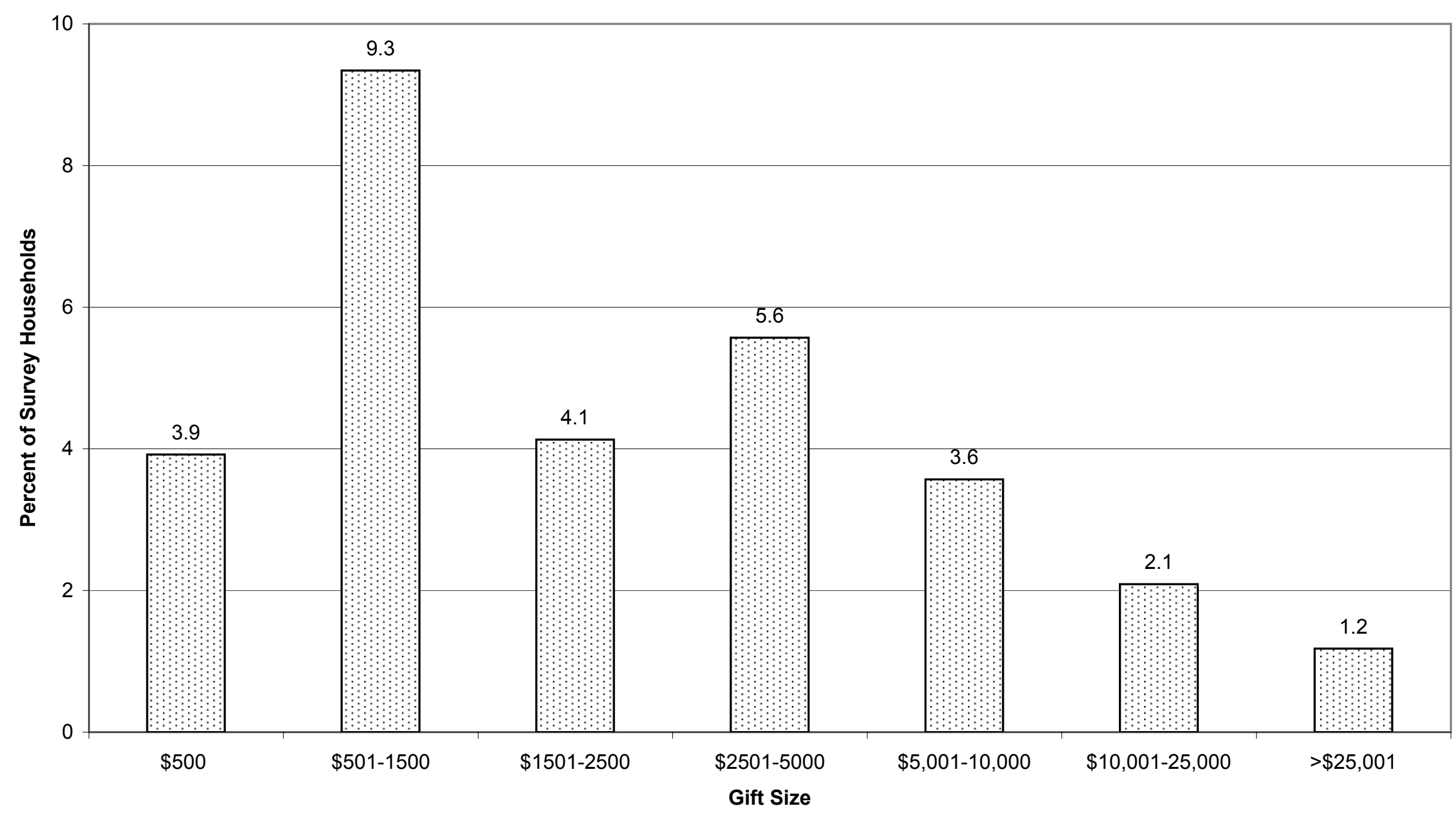


Table 1

Expenditures on Nursing Home Care, by Payment Source, Various Years

\begin{tabular}{|c|c|c|c|c|c|}
\hline Year & Total & $\begin{array}{c}\text { Out-of-Pocket } \\
\text { Payments }\end{array}$ & $\begin{array}{c}\text { Private Third- } \\
\text { Party } \\
\text { Payments }\end{array}$ & $\begin{array}{c}\text { Non-Medicaid } \\
\text { Government } \\
\text { Payments }\end{array}$ & $\begin{array}{l}\text { Medicaid } \\
\text { Payments }\end{array}$ \\
\hline & \multicolumn{5}{|c|}{ Amount in Billions } \\
\hline 1970 & 4.2 & & & & \\
\hline 1980 & 17.7 & 7.1 & 1.0 & 0.7 & 8.9 \\
\hline 1988 & 40.5 & 15.6 & 4.9 & 1.7 & 18.4 \\
\hline 1990 & 52.7 & 19.8 & 7.0 & 2.7 & 23.2 \\
\hline 1993 & 65.7 & 19.6 & 8.3 & 5.4 & 32.4 \\
\hline 1995 & 74.6 & 19.9 & 10.4 & 8.9 & 35.4 \\
\hline 1997 & 85.1 & 21.8 & 12.3 & 11.4 & 39.6 \\
\hline 1999 & 89.6 & 25.4 & 12.0 & 10.4 & 41.8 \\
\hline 2001 & 98.9 & 26.9 & 11.2 & 13.9 & 47.0 \\
\hline
\end{tabular}

SOURCE: http://cms.hhs.gov/statistics/nhe/historical/t7.asp. Centers for Medicare \&

Medicaid Services, Office of the Actuary, National Health Statistics Group; U.S. Bureau of the Census. 
Table 2

\section{Incidence and Size of Asset Transfers}

by Probability of using a nursing home and marital status

\begin{tabular}{|c|c|c|c|c|c|c|}
\hline \multirow{2}{*}{\multicolumn{2}{|c|}{\begin{tabular}{|l} 
Respondent \\
Probability
\end{tabular}}} & \multirow{2}{*}{$\begin{array}{r}\text { Single } \\
\text { Respondent }\end{array}$} & \multicolumn{4}{|c|}{ Spouse Probability } \\
\hline & & & $0-2$ & $3-19$ & $20-59$ & $>60$ \\
\hline \multirow[t]{3}{*}{$0-2$} & Fraction & 0.247 & 0.337 & 0.420 & 0.399 & 0.369 \\
\hline & Amount & $\$ 5,682$ & $\$ 4,344$ & $\$ 4,847$ & $\$ 3,516$ & $\$ 6,507$ \\
\hline & $\mathrm{N}$ & 1268 & 500 & 83 & 102 & 22 \\
\hline \multirow[t]{3}{*}{ 3-19 } & Fraction & 0.321 & 0.341 & 0.335 & 0.348 & 0.369 \\
\hline & Amount & $\$ 6,392$ & $\$ 5,700$ & $\$ 3,733$ & $\$ 5,330$ & $\$ 2,758$ \\
\hline & $\mathrm{N}$ & 228 & 97 & 31 & 57 & 6 \\
\hline \multirow[t]{3}{*}{$20-59$} & Fraction & 0.302 & 0.423 & 0.328 & 0.458 & 0.496 \\
\hline & Amount & $\$ 4,700$ & $\$ 6,592$ & $\$ 6,977$ & $\$ 8,318$ & $\$ 1,390$ \\
\hline & $\mathrm{N}$ & 525 & 157 & 33 & 96 & 14 \\
\hline \multirow[t]{3}{*}{$>60$} & Fraction & 0.245 & 0.546 & 0.747 & 0.686 & 0.678 \\
\hline & Amount & $\$ 1,990$ & $\$ 2,769$ & $\$ 3,252$ & $\$ 7,098$ & $\$ 3,080$ \\
\hline & $\mathrm{N}$ & 134 & 14 & 5 & 17 & 4 \\
\hline \multicolumn{7}{|c|}{ Memo: Summary Statistics } \\
\hline & & & & Average Gift & & Non-Exempt \\
\hline \multirow{2}{*}{\multicolumn{2}{|c|}{ Observations }} & Gave Gift & Average Gift & if Gave Gift & House Value & Net Worth \\
\hline & & 3393 & 3393 & 1007 & 3393 & 3393 \\
\hline \multicolumn{2}{|l|}{ Mean } & 0.313 & $\$ 1,639$ & $\$ 4,981$ & $\$ 81,154$ & $\$ 112,589$ \\
\hline \multicolumn{2}{|c|}{ Std. Dev. } & 0.464 & $\$ 5,929$ & $\$ 8,679$ & $\$ 153,465$ & $\$ 378,995$ \\
\hline \multicolumn{2}{|c|}{ Minimum } & 0 & $\$ 0$ & $\$ 500$ & $\$ 0$ & $-\$ 159,500$ \\
\hline \multicolumn{2}{|c|}{ Maximum } & 1 & $\$ 127,000$ & $\$ 127,000$ & $\$ 5,000,000$ & $\$ 12,607,707$ \\
\hline
\end{tabular}


Table 3

Summary Statistics for Analysis Variables

Number of observations: 3393

Variable

$\log$ (Pension and annuity income)

$\log$ (Social security income)

Manager/Professional

Sp. Manager/Professional

High School

Some college

College grad

Sp. High school

Sp. Some college

Sp. College grad

Sex of respondent

Married

Widowed

Divorce

White

Age - 70

Sp. Age-70

No kids

Number of kids

Number of kids own their home

Number of kids married

Number of male kids

Number of grandkids

Number of Living parents

Sp. Number of Living parents

Volunteer work

Sp. Volunteer work

$\mathrm{P}$ (Live 10 years)

Sp. P(Live 10 years)

Good health

Bad health

Sp. Good health

Sp. Bad health

Medical need statute applies

State Medicaid asset limit/1000

State Medicaid income limit/1000

Number of $\mathrm{NH}$ Beds $/ 1000$ elderly

$\mathrm{P}$ (Use NH in next 5 years)

Sp. $\mathrm{P}$ (Use NH in next 5 years)
Mean Std. Dev. Minimum Maximum

$\begin{array}{rrrr}4.75 & 4.37 & 0 & 11.48 \\ 8.87 & 1.56 & 0 & 10.41 \\ 0.275 & 0.447 & 0 & 1 \\ 0.193 & 0.395 & 0 & 1 \\ 0.331 & 0.471 & 0 & 1 \\ 0.184 & 0.387 & 0 & 1 \\ 0.154 & 0.361 & 0 & 1 \\ 0.360 & 0.480 & 0 & 1 \\ 0.137 & 0.344 & 0 & 1 \\ 0.136 & 0.343 & 0 & 1 \\ 0.393 & 0.488 & 0 & 1 \\ 0.395 & 0.489 & 0 & 1 \\ 0.508 & 0.500 & 0 & 1 \\ 0.068 & 0.251 & 0 & 1 \\ 0.939 & 0.240 & 0 & 1 \\ 6.0 & 5.5 & -23 & 20 \\ 1.0 & 4.2 & -32 & 19 \\ 0.112 & 0.315 & 0 & 1 \\ 2.9 & 2.2 & 0 & 18 \\ 1.9 & 1.6 & 0 & 10 \\ 1.9 & 1.6 & 0 & 13 \\ 1.3 & 1.3 & 0 & 9 \\ 5.7 & 5.8 & 0 & 48 \\ 0.03 & 0.19 & 0 & 2 \\ 0.03 & 0.19 & 0 & 2 \\ 0.168 & 0.374 & 0 & 1 \\ 0.068 & 0.251 & 0 & 1 \\ 0.434 & 0.341 & 0 & 1 \\ 0.188 & 0.312 & 0 & 1 \\ 0.404 & 0.491 & 0 & 1 \\ 0.281 & 0.449 & 0 & 1 \\ 0.163 & 0.370 & 0 & 1 \\ 0.113 & 0.317 & 0 & 1 \\ 0.854 & 0.353 & 0 & 1 \\ 16.857 & 24.939 & 1.000 & 73.193 \\ 0.589 & 0.708 & 0.030 & 1.840 \\ 25.4 & 8.9 & 13.1 & 45.2 \\ 0.147 & 0.232 & 0 & 1 \\ 0.049 & 0.147 & 0 & 1\end{array}$


Table 4

Regression of Gave Gift on Various Financial, Demographic, and Health Characteristics

Number of observations: 3393; number of gifts given 1007

Log Liklihood

$-1842.45$

arginal

\begin{tabular}{|c|c|c|c|c|c|c|c|c|c|c|c|c|}
\hline \multirow[b]{2}{*}{ Parameter } & \multirow{2}{*}{$\begin{array}{r}\text { Marginal } \\
\text { Effect }\end{array}$} & \multicolumn{2}{|c|}{ Standard } & \multirow{2}{*}{$\begin{array}{r}\text { Marginal } \\
\text { Effect }\end{array}$} & \multicolumn{2}{|c|}{ Standard } & \multirow{2}{*}{$\begin{array}{r}\text { Marginal } \\
\text { Effect }\end{array}$} & \multicolumn{2}{|c|}{ Standard } & \multirow{2}{*}{$\begin{array}{r}\text { Marginal } \\
\text { Effect }\end{array}$} & \multicolumn{2}{|c|}{ Standard } \\
\hline & & Coeff. & Error & & Coeff. & Error & & Coeff. & Error & & Coeff. & Error \\
\hline Intercept & -0.596 & -1.728 & $0.265^{* * *}$ & -0.599 & -1.743 & $0.266^{* * *}$ & -0.599 & -1.742 & $0.266^{* * *}$ & -0.595 & -1.720 & $0.265^{* * *}$ \\
\hline $\log ($ Pension income $)$ & 0.037 & 0.024 & $0.006^{* * *}$ & 0.036 & 0.024 & $0.006^{* * *}$ & 0.037 & 0.024 & $0.006^{* * *}$ & 0.036 & 0.024 & $0.006^{* * *}$ \\
\hline og(SS income) & 0.028 & 0.053 & $0.017^{* * *}$ & 0.028 & 0.053 & $0.017^{* * *}$ & 0.028 & 0.053 & $0.017^{* * *}$ & 0.028 & 0.052 & $0.017^{* * *}$ \\
\hline Professional & 0.050 & 0.148 & $0.062 * *$ & 0.050 & 0.148 & $0.062 * *$ & 0.051 & 0.149 & $0.062 * *$ & 0.050 & 0.147 & $0.062 * *$ \\
\hline Sp. Professional & 0.083 & 0.240 & $0.068^{* * *}$ & 0.084 & 0.241 & $0.068^{* * *}$ & 0.083 & 0.241 & $0.068^{* * *}$ & 0.083 & 0.238 & $0.068^{* * *}$ \\
\hline High School & 0.114 & 0.332 & $0.066^{* * *}$ & 0.113 & 0.329 & $0.066^{* * *}$ & 0.114 & 0.332 & $0.066^{* * *}$ & 0.114 & 0.331 & $0.066^{* * *}$ \\
\hline Some college & 0.162 & 0.453 & $0.079^{* * *}$ & 0.160 & 0.450 & $0.079^{* * *}$ & 0.161 & 0.452 & $0.079^{* * *}$ & 0.161 & 0.451 & $0.079 * * *$ \\
\hline College grad & 0.190 & 0.525 & $0.094^{* * *}$ & 0.188 & 0.520 & $0.094^{* * *}$ & 0.188 & 0.521 & $0.094^{* * *}$ & 0.184 & 0.509 & $0.098 * * *$ \\
\hline Sp. High school & 0.013 & 0.040 & 0.063 & 0.013 & 0.038 & 0.063 & 0.013 & 0.038 & 0.063 & 0.013 & 0.039 & 0.063 \\
\hline Sp. Some college & 0.041 & 0.120 & 0.085 & 0.041 & 0.120 & 0.085 & 0.040 & 0.118 & 0.085 & 0.041 & 0.119 & 0.085 \\
\hline Sp. College grad & 0.076 & 0.219 & $0.092 * *$ & 0.075 & 0.215 & $0.092^{* *}$ & 0.074 & 0.214 & $0.092^{* *}$ & 0.070 & 0.201 & $0.096 * *$ \\
\hline Sex of respondent & 0.069 & 0.205 & $0.059 * * *$ & 0.069 & 0.205 & $0.059 * * *$ & 0.069 & 0.203 & $0.059 * * *$ & 0.069 & 0.205 & $0.059 * * *$ \\
\hline Married & 0.040 & 0.118 & 0.276 & 0.035 & 0.104 & 0.277 & 0.034 & 0.103 & 0.277 & 0.040 & 0.120 & 0.276 \\
\hline Widowed & -0.001 & -0.003 & 0.176 & 0.002 & 0.006 & 0.177 & 0.002 & 0.005 & 0.177 & -0.001 & -0.002 & 0.176 \\
\hline Divorce & -0.011 & -0.032 & 0.192 & -0.007 & -0.023 & 0.192 & -0.008 & -0.025 & 0.192 & 10 & -0.031 & 0.192 \\
\hline White & 0.066 & 0.209 & 0.089 ** & 0.065 & 0.208 & $0.089^{* *}$ & 0.066 & 0.210 & $0.089 * *$ & 0.066 & 0.210 & 39 ** \\
\hline Age -70 & -0.015 & -0.009 & 0.0 & 15 & -0.008 & 0.005 & 15 & -0.008 & 0.005 & 0.016 & -0.009 & $0.005^{*}$ \\
\hline Sp. Age-70 & 0.001 & 0.001 & 0.007 & 0.002 & 0.001 & 0.007 & 0.001 & 0.001 & 0.007 & 0.001 & 0.001 & 0.007 \\
\hline No kids & -0.126 & -0.426 & $0.099 * * *$ & -0.125 & -0.420 & $0.099 * * *$ & -0.125 & -0.421 & $0.099 * * *$ & -0.126 & -0.427 & $0.099 * * *$ \\
\hline Number of kids & 0.037 & 0.050 & $0.023^{* *}$ & 0.037 & 0.050 & $0.023^{* *}$ & 038 & 0.051 & $0.023^{* *}$ & 0.037 & 0.050 & $0.023 * *$ \\
\hline Kids house & -0.013 & -0.039 & 0.030 & -0.014 & -0.039 & 0.030 & 0.014 & -0.040 & 0.030 & 0.013 & -0.038 & 0.030 \\
\hline Kids married & -0.022 & -0.063 & 0.034 * & -0.022 & -0.062 & 0.034 * & -0.022 & -0.063 & 0.034 * & 0.022 & -0.063 & 0.034 * \\
\hline Kids male & 0.009 & 0.028 & 0.027 & 0.009 & 0.029 & 0.027 & 0.010 & 0.029 & 0.027 & 0.009 & 0.028 & 0.027 \\
\hline Grandkids & -0.015 & -0.008 & 0.007 & -0.015 & -0.008 & 0.007 & -0.015 & -0.008 & 0.007 & -0.015 & -0.008 & 0.007 \\
\hline Living parents & -0.050 & -0.156 & 0.137 & -0.046 & -0.145 & 0.137 & -0.048 & -0.152 & 0.137 & -0.049 & -0.154 & 0.137 \\
\hline Sp. Living parents & -0.049 & -0.154 & 0.151 & -0.047 & -0.147 & 0.152 & -0.048 & -0.152 & 0.152 & -0.049 & -0.156 & 0.152 \\
\hline Volunteer work & 0.001 & 0.002 & 0.066 & 0.000 & -0.001 & 0.066 & 0.000 & 0.000 & 0.066 & 0.001 & 0.002 & 0.066 \\
\hline Sp. Volunteer work & -0.047 & -0.147 & 0.106 & -0.048 & -0.151 & 0.107 & -0.049 & -0.153 & 0.107 & -0.047 & -0.146 & 0.106 \\
\hline
\end{tabular}

$-1841.85$

$-1842.25$

$-1840.99$

\begin{tabular}{|c|c|c|c|c|c|c|c|c|c|c|c|c|}
\hline \multirow[b]{2}{*}{ Parameter } & \multirow{2}{*}{$\begin{array}{r}\text { Marginal } \\
\text { Effect }\end{array}$} & \multicolumn{2}{|c|}{ Standard } & \multirow{2}{*}{$\begin{array}{r}\text { Marginal } \\
\text { Effect }\end{array}$} & \multicolumn{2}{|c|}{ Standard } & \multirow{2}{*}{$\begin{array}{r}\text { Marginal } \\
\text { Effect }\end{array}$} & \multicolumn{2}{|c|}{ Standard } & \multirow{2}{*}{$\begin{array}{r}\text { Marginal } \\
\text { Effect }\end{array}$} & \multicolumn{2}{|c|}{ Standard } \\
\hline & & Coeff. & Error & & Coeff. & Error & & Coeff. & Error & & Coeff. & Error \\
\hline Intercept & -0.596 & -1.728 & $0.265^{* * *}$ & -0.599 & -1.743 & $0.266^{* * *}$ & -0.599 & -1.742 & $0.266^{* * *}$ & -0.595 & -1.720 & $0.265^{* * *}$ \\
\hline $\log ($ Pension income $)$ & 0.037 & 0.024 & $0.006^{* * *}$ & 0.036 & 0.024 & $0.006^{* * *}$ & 0.037 & 0.024 & $0.006^{* * *}$ & 0.036 & 0.024 & $0.006^{* * *}$ \\
\hline og(SS income) & 0.028 & 0.053 & $0.017^{* * *}$ & 0.028 & 0.053 & $0.017^{* * *}$ & 0.028 & 0.053 & $0.017^{* * *}$ & 0.028 & 0.052 & $0.017^{* * *}$ \\
\hline Professional & 0.050 & 0.148 & $0.062 * *$ & 0.050 & 0.148 & $0.062 * *$ & 0.051 & 0.149 & $0.062 * *$ & 0.050 & 0.147 & $0.062 * *$ \\
\hline Sp. Professional & 0.083 & 0.240 & $0.068^{* * *}$ & 0.084 & 0.241 & $0.068^{* * *}$ & 0.083 & 0.241 & $0.068^{* * *}$ & 0.083 & 0.238 & $0.068^{* * *}$ \\
\hline High School & 0.114 & 0.332 & $0.066^{* * *}$ & 0.113 & 0.329 & $0.066^{* * *}$ & 0.114 & 0.332 & $0.066^{* * *}$ & 0.114 & 0.331 & $0.066^{* * *}$ \\
\hline Some college & 0.162 & 0.453 & $0.079^{* * *}$ & 0.160 & 0.450 & $0.079^{* * *}$ & 0.161 & 0.452 & $0.079^{* * *}$ & 0.161 & 0.451 & $0.079 * * *$ \\
\hline College grad & 0.190 & 0.525 & $0.094^{* * *}$ & 0.188 & 0.520 & $0.094^{* * *}$ & 0.188 & 0.521 & $0.094^{* * *}$ & 0.184 & 0.509 & $0.098 * * *$ \\
\hline Sp. High school & 0.013 & 0.040 & 0.063 & 0.013 & 0.038 & 0.063 & 0.013 & 0.038 & 0.063 & 0.013 & 0.039 & 0.063 \\
\hline Sp. Some college & 0.041 & 0.120 & 0.085 & 0.041 & 0.120 & 0.085 & 0.040 & 0.118 & 0.085 & 0.041 & 0.119 & 0.085 \\
\hline Sp. College grad & 0.076 & 0.219 & $0.092 * *$ & 0.075 & 0.215 & $0.092^{* *}$ & 0.074 & 0.214 & $0.092^{* *}$ & 0.070 & 0.201 & $0.096 * *$ \\
\hline Sex of respondent & 0.069 & 0.205 & $0.059 * * *$ & 0.069 & 0.205 & $0.059 * * *$ & 0.069 & 0.203 & $0.059 * * *$ & 0.069 & 0.205 & $0.059 * * *$ \\
\hline Married & 0.040 & 0.118 & 0.276 & 0.035 & 0.104 & 0.277 & 0.034 & 0.103 & 0.277 & 0.040 & 0.120 & 0.276 \\
\hline Widowed & -0.001 & -0.003 & 0.176 & 0.002 & 0.006 & 0.177 & 0.002 & 0.005 & 0.177 & -0.001 & -0.002 & 0.176 \\
\hline Divorce & -0.011 & -0.032 & 0.192 & -0.007 & -0.023 & 0.192 & -0.008 & -0.025 & 0.192 & 10 & -0.031 & 0.192 \\
\hline White & 0.066 & 0.209 & 0.089 ** & 0.065 & 0.208 & $0.089^{* *}$ & 0.066 & 0.210 & $0.089 * *$ & 0.066 & 0.210 & 39 ** \\
\hline Age -70 & -0.015 & -0.009 & 0.0 & 15 & -0.008 & 0.005 & 15 & -0.008 & 0.005 & 0.016 & -0.009 & $0.005^{*}$ \\
\hline Sp. Age-70 & 0.001 & 0.001 & 0.007 & 0.002 & 0.001 & 0.007 & 0.001 & 0.001 & 0.007 & 0.001 & 0.001 & 0.007 \\
\hline No kids & -0.126 & -0.426 & $0.099 * * *$ & -0.125 & -0.420 & $0.099 * * *$ & -0.125 & -0.421 & $0.099 * * *$ & -0.126 & -0.427 & $0.099 * * *$ \\
\hline Number of kids & 0.037 & 0.050 & $0.023^{* *}$ & 0.037 & 0.050 & $0.023^{* *}$ & 038 & 0.051 & $0.023^{* *}$ & 0.037 & 0.050 & $0.023 * *$ \\
\hline Kids house & -0.013 & -0.039 & 0.030 & -0.014 & -0.039 & 0.030 & 0.014 & -0.040 & 0.030 & 0.013 & -0.038 & 0.030 \\
\hline Kids married & -0.022 & -0.063 & 0.034 * & -0.022 & -0.062 & 0.034 * & -0.022 & -0.063 & 0.034 * & 0.022 & -0.063 & 0.034 * \\
\hline Kids male & 0.009 & 0.028 & 0.027 & 0.009 & 0.029 & 0.027 & 0.010 & 0.029 & 0.027 & 0.009 & 0.028 & 0.027 \\
\hline Grandkids & -0.015 & -0.008 & 0.007 & -0.015 & -0.008 & 0.007 & -0.015 & -0.008 & 0.007 & -0.015 & -0.008 & 0.007 \\
\hline Living parents & -0.050 & -0.156 & 0.137 & -0.046 & -0.145 & 0.137 & -0.048 & -0.152 & 0.137 & -0.049 & -0.154 & 0.137 \\
\hline Sp. Living parents & -0.049 & -0.154 & 0.151 & -0.047 & -0.147 & 0.152 & -0.048 & -0.152 & 0.152 & -0.049 & -0.156 & 0.152 \\
\hline Volunteer work & 0.001 & 0.002 & 0.066 & 0.000 & -0.001 & 0.066 & 0.000 & 0.000 & 0.066 & 0.001 & 0.002 & 0.066 \\
\hline Sp. Volunteer work & -0.047 & -0.147 & 0.106 & -0.048 & -0.151 & 0.107 & -0.049 & -0.153 & 0.107 & -0.047 & -0.146 & 0.106 \\
\hline
\end{tabular}




\begin{tabular}{|c|c|c|c|c|c|c|c|c|c|c|c|c|}
\hline $\mathrm{P}$ (Live 10 years) & -0.010 & -0.089 & 0.077 & -0.010 & -0.085 & 0.077 & -0.010 & -0.085 & 0.077 & -0.010 & -0.088 & 0.077 \\
\hline Good health & 0.006 & 0.018 & 0.058 & 0.006 & 0.018 & 0.058 & 0.006 & 0.019 & 0.058 & 0.006 & 0.019 & 0.058 \\
\hline Bad health & -0.039 & -0.119 & 0.065 * & -0.039 & -0.119 & $0.065 *$ & -0.038 & -0.117 & $0.065 *$ & -0.039 & -0.119 & $0.065 *$ \\
\hline Sp. Good health & 0.056 & 0.163 & 0.093 * & 0.056 & 0.164 & 0.093 * & 0.060 & 0.174 & 0.093 * & 0.057 & 0.165 & 0.093 * \\
\hline Medical need laws & 0.021 & 0.063 & 0.073 & 0.021 & 0.063 & 0.073 & 0.019 & 0.059 & 0.073 & 0.021 & 0.063 & 0.073 \\
\hline Asset Limit & -0.003 & 0.000 & 0.002 & -0.003 & 0.000 & 0.002 & -0.003 & 0.000 & 0.002 & -0.003 & 0.000 & 0.002 \\
\hline Income Limit & -0.003 & -0.014 & 0.154 & -0.003 & -0.015 & 0.154 & -0.004 & -0.016 & 0.155 & -0.004 & -0.016 & 0.154 \\
\hline Sp. P(NH) & 0.019 & 0.372 & $0.183^{* *}$ & 0.038 & 0.749 & 0.497 & & & & 0.018 & 0.365 & $0.215^{*}$ \\
\hline $\mathrm{P}(\mathrm{NH})^{* *} 2$ & & & & -0.015 & -0.264 & 0.382 & & & & & & \\
\hline Sp. $\mathrm{P}(\mathrm{NH})^{* *} 2$ & & & & -0.019 & -0.597 & 0.725 & & & & & & \\
\hline $\mathrm{P}(\mathrm{NH})^{*}$ college grad & & & & & & & & & & 0.006 & 0.139 & 0.223 \\
\hline Sp. $\mathrm{P}(\mathrm{NH})^{*}$ college & & & & & & & & & & 0.001 & 0.026 & 0.343 \\
\hline $20<P(N H)<60$ & & & & & & & 0.035 & 0.103 & 0.057 * & & & \\
\hline for $\mathrm{P}(\mathrm{NH})$ variables & & 9.16 & 0.010 & & 10.36 & 0.035 & & 12.08 & 0.017 & & 9.56 & 0.048 \\
\hline
\end{tabular}

Note: For continuous variables, the marginal effects are calculated as the change in the predicted probability from a one-standard-deviation increase in the independent variable. For dichotomous variables, the marginal effects are calculated as the change in the predicted probability when switching the value of the independent variable from 0 to 1 . All other variables are evaluated at their means. 
Table 5

OLS Regressions of Total Gifts on Financial, Demographic, and Health Characteristics Number of observations: 1007

\begin{tabular}{|c|c|c|c|c|c|c|}
\hline \multirow{2}{*}{$\begin{array}{l}\text { Adj. R-Sq } \\
\text { Variable }\end{array}$} & \multicolumn{2}{|l|}{0.043} & \multicolumn{2}{|l|}{0.044} & \multicolumn{2}{|l|}{0.045} \\
\hline & Estimate & Error & Estimate & Error & Estimate & Error \\
\hline Intercept & 7.195 & $0.461^{* * *}$ & 7.155 & $0.462^{* * *}$ & 7.217 & $\overline{0.461} * *$ \\
\hline $\log ($ Pension income $)$ & -0.020 & $0.009 * *$ & -0.021 & $0.009 * *$ & -0.021 & $0.009 * *$ \\
\hline $\log (S S$ income) & 0.049 & 0.027 * & 0.050 & 0.027 * & 0.047 & 0.027 * \\
\hline Professional & 0.156 & 0.089 * & 0.156 & 0.089 * & 0.163 & 0.089 * \\
\hline Sp. Professional & 0.026 & 0.095 & 0.035 & 0.095 & 0.036 & 0.095 \\
\hline High School & 0.091 & 0.115 & 0.099 & 0.115 & 0.098 & 0.115 \\
\hline Some college & 0.283 & $0.130 * *$ & 0.287 & $0.131 * *$ & 0.275 & 0.130 ** \\
\hline College grad & 0.302 & $0.144 * *$ & 0.309 & $0.145^{* *}$ & 0.307 & 0.144 ** \\
\hline Sp. High school & 0.052 & 0.103 & 0.041 & 0.104 & 0.036 & 0.103 \\
\hline Sp. Some college & 0.171 & 0.131 & 0.173 & 0.131 & 0.165 & 0.131 \\
\hline Sp. College grad & 0.156 & 0.137 & 0.142 & 0.138 & 0.151 & 0.137 \\
\hline Sex of respondent & 0.055 & 0.093 & 0.060 & 0.093 & 0.057 & 0.093 \\
\hline Married & -1.025 & $0.437^{* *}$ & -1.057 & $0.439 * *$ & -1.072 & 0.437 ** \\
\hline Widowed & -0.488 & 0.319 & -0.473 & 0.319 & -0.506 & 0.319 \\
\hline Divorce & -0.568 & 0.344 * & -0.556 & 0.344 & -0.583 & 0.343 * \\
\hline White & 0.319 & 0.152 ** & 0.314 & $0.152 * *$ & 0.326 & 0.152 ** \\
\hline Age - 70 & 0.003 & 0.008 & 0.003 & 0.008 & 0.003 & 0.008 \\
\hline Sp. Age-70 & 0.029 & $0.010 * * *$ & 0.029 & $0.010^{* * *}$ & 0.030 & $0.010 * *$ \\
\hline No kids & -0.215 & 0.177 & -0.215 & 0.177 & -0.219 & 0.176 \\
\hline Number of kids & -0.007 & 0.037 & -0.006 & 0.037 & -0.007 & 0.037 \\
\hline Kids house & 0.095 & $0.048 * *$ & 0.090 & 0.048 * & 0.094 & 0.048 * \\
\hline Kids married & -0.064 & 0.051 & -0.060 & 0.051 & -0.063 & 0.051 \\
\hline Kids male & 0.054 & 0.043 & 0.056 & 0.044 & 0.052 & 0.043 \\
\hline Grandkids & -0.018 & 0.013 & -0.018 & 0.013 & -0.018 & 0.013 \\
\hline Living parents & 0.054 & 0.204 & 0.077 & 0.205 & 0.093 & 0.223 \\
\hline Sp. Living parents & 0.513 & $0.219 * *$ & 0.542 & $0.220 * *$ & 0.749 & $0.245 * *$ \\
\hline Volunteer work & -0.036 & 0.098 & -0.039 & 0.099 & -0.038 & 0.098 \\
\hline Sp. Volunteer work & 0.003 & 0.150 & -0.006 & 0.150 & 0.003 & 0.149 \\
\hline $\mathrm{P}$ (Live 10 years) & -0.076 & 0.126 & -0.072 & 0.126 & -0.075 & 0.125 \\
\hline Sp. P(Live 10 years) & 0.122 & 0.183 & 0.128 & 0.183 & 0.099 & 0.183 \\
\hline Good health & -0.003 & 0.088 & 0.001 & 0.088 & -0.001 & 0.087 \\
\hline Bad health & -0.023 & 0.107 & -0.018 & 0.107 & -0.004 & 0.107 \\
\hline Sp. Good health & 0.097 & 0.131 & 0.102 & 0.131 & 0.102 & 0.131 \\
\hline Sp. Bad health & 0.130 & 0.157 & 0.142 & 0.158 & 0.132 & 0.157 \\
\hline Medical need laws & -0.018 & 0.116 & -0.018 & 0.116 & -0.008 & 0.116 \\
\hline Asset Limit & -0.004 & 0.002 * & -0.004 & 0.002 * & -0.004 & 0.002 * \\
\hline Income Limit & 0.319 & 0.219 & 0.319 & 0.219 & 0.314 & 0.218 \\
\hline NH Beds/1000 & 0.005 & 0.004 & 0.006 & 0.004 & 0.005 & 0.004 \\
\hline $\mathrm{P}(\mathrm{NH})$ & -0.114 & 0.167 & 0.213 & 0.440 & & \\
\hline Sp. $\mathrm{P}(\mathrm{NH})$ & -0.085 & 0.258 & 0.671 & 0.686 & & \\
\hline $\mathrm{P}(\mathrm{NH})^{* *} 2$ & & & -0.494 & 0.597 & & \\
\hline Sp. $\mathrm{P}(\mathrm{NH})^{* *} 2$ & & & -1.178 & 0.982 & & \\
\hline $20<P(N H)<60$ & & & & & -0.018 & 0.086 \\
\hline $\mathrm{P}(\mathrm{NH})>60$ & & & & & -0.301 & 0.173 * \\
\hline $20<$ Sp. $P(N H)<60$ & & & & & 0.095 & 0.133 \\
\hline Sp. $P(N H)>60$ & & & & & -0.368 & 0.266 \\
\hline Mills Ratio & 0.049 & 0.149 & 0.000 & 0.149 & 0.027 & 0.149 \\
\hline & F-Stat & $\mathrm{P}>\mathrm{F}$-Stat & F-Stat & $\mathrm{P}>\mathrm{F}-\mathrm{Stat}$ & F-Stat & $>$ F-Stat \\
\hline Joint Test of $\mathrm{P}(\mathrm{NH})$ & 0.30 & 0.74 & 0.68 & 0.60 & 1.42 & 0.23 \\
\hline
\end{tabular}


Table 6

Calculation of Fiscal Effects of Medicaid-Induced Asset Transfers

AHEAD Population

Sample Over Age 65

1. Number of elderly households

2. Fraction of AHEAD potentially eligible for Medicaid

$21,400,000$

3. Number potentially eligible for Medicaid

4. Fraction of AHEAD potentially eligible that made a gift

$12,240,800$

5. Number potentially eligible that made gift

6. Average gift conditional on making a transfer

0.572

0.357

7. Predicted transfers for whole elderly population

$\$ 4,936$

$4,369,966$

$\$ 21,570,150,202$

8. Fraction of all households with transfers attributable to nursing homes

0.018

9. Number that wouldn't give if coefficient $=0$ (line 8 * line 1$)$ 220,334

10. Amount transferred by those households (line 9 * line 6)

$\$ 1,087,570,598$

Source: U.S. Bureau of the Census, Current Population Reports, P25-119 and author's estimates 